\title{
Interprofessional learning issues in postgraduate mental health education
}

\author{
Victoria Stewart \\ Griffith University \\ Michelle Crozier \\ Griffith University \\ Amanda Wheeler \\ Griffith University
}

\begin{abstract}
Interprofessional care within many clinical and community mental health teams in Australia require staff to work collaboratively and outside their traditional scope. Whilst shared decision making and interprofessional collaboration are important approaches in supporting an individual's recovery journey, working interprofessionally can create issues within teams when determining and defining ways to respond, care and support people with mental illness. The aim of this report is to examine workforce perspectives regarding an interprofessional postgraduate learning approach in mental health practice. Semistructured in-depth interviews were conducted with eight mental health stakeholders. Findings indicate that practitioner learning needs are dependent on practice setting (i.e. hospital/clinical vs. community) and professional background (i.e. social work, nursing). Learning needs were related to the application of practice frameworks (therapeutic relationship, recovery and professional identity) and the workforce issues for employers (qualifications and skills). Overall interprofessional understanding and collaboration were seen as an essential requirement in ensuring an evidence based response to improve quality of life and economic and social participation for consumers. Tension between professional identities and the need for mental health practitioners to operate successfully within interprofessional contexts provides a challenge for postgraduate higher education providers.
\end{abstract}

Keywords: Inter-professional; multidisciplinary; mental health; postgraduate; higher education

In recent decades, recovery has emerged as a major paradigm within the mental health field, supporting consumer choice, active participation and involvement in decision making. Within current Australian mental health policy (Commonwealth of Australia, 2009, p. 31), recovery is defined as "a personal process of changing one's attitudes, values, feelings, goals, skills and/or roles. It involves the development of new meaning and purpose and a satisfying, hopeful and contributing life as the person grows beyond the effects of psychiatric disability". Recovery cannot exist without social inclusion and socially inclusive opportunities to support recovery (Currie, 2011).

Despite recent policy initiatives, Australia continues to grapple with providing coordinated, comprehensive and effective mental health services which meet the needs and demands of the community and support individuals in their recovery journeys (Meadows \& Burgess, 2009). It is increasingly being seen as important to develop multidisciplinary, creative and flexible

Corresponding Author: Victoria Stewart (v.stewart@griffith.edu.au) 
healthcare teams to meet future, person-centred service responses (Duckett, 2005; Vize, 2009). Australia's healthcare workforce arrangements are complex, interdependent and arguments about specialisation and interprofessional care models are ongoing (McAllister et al., 2014; Productivity Commission, 2005). This trend has also dominated the workforce in the United Kingdom (U.K.) with ongoing discussion regarding the roles of community mental health nurses and social workers with increased overlapping and generalisation of skills (Hannigan \& Allen, 2011).

In response to workforce concerns, both the Australian and U.K. governments have identified the need to facilitate workforce skills and drive reforms in the scopes of practice for health professionals. Mental health practitioners have increasingly identified both blurring and confusion of generic versus professional roles, combined with conflicting disciplinary priorities impacting on communication and coordination of care (Henderson, Willis, Walter, \& Toffoli, 2008). Interprofessional understanding and collaboration therefore is vital to ensure that holistic, evidence based and respectful approaches to care and support are provided. Interprofessional education (IPE) has been identified as an effective pedagogical means of improving interprofessional collaboration (Barr, Koppel, Reeves, Hammick, \& Freeth, 2005), however, within Australian universities, it has been identified that IPE is largely fragmented, minimally resourced and existing on the margins of curriculum (McAllister et al., 2014; The Interprofessional Curriculum Renewal Consortium Australia, 2013).

This study was undertaken as part of an evaluation of a postgraduate mental health practice program at an Australian University (Stewart, Fielden, Harris, \& Wheeler, 2012). The program (operating since 2009) was developed to provide practitioners from different professional backgrounds the knowledge and skills to support people with mental illness. This program is delivered on-line and enables practitioners from a diverse range of backgrounds to learn collaboratively and interprofessionally, exploring challenges in current mental health service delivery. Table 1 provides an overview of the program content.

Table 1. Graduate Certificate and Master of Mental Health Practice Program*

\begin{tabular}{|c|c|}
\hline Course Title & Course Summary \\
\hline $\begin{array}{l}\text { Understanding Mental } \\
\text { Health: Theories and } \\
\text { Practice }\end{array}$ & $\begin{array}{l}\text { Historical understandings of mental illness, epidemiology and theoretical } \\
\text { frameworks influencing practice. Introduces students to current } \\
\text { psychiatric classification systems, assessment skills and knowledge of } \\
\text { major categories of psychiatric diagnoses and symptoms. }\end{array}$ \\
\hline $\begin{array}{l}\text { Consumer, Carer, and } \\
\text { Community } \\
\text { Engagement in Mental } \\
\text { Health }\end{array}$ & $\begin{array}{l}\text { Introduces students to concepts of consumer rights and explores } \\
\text { consumer perspectives on living with mental health problems. It also } \\
\text { covers issues for carers and families in working collaboratively with } \\
\text { mental health services, and introduces students to concepts of } \\
\text { community engagement and advocacy in a mental health context. }\end{array}$ \\
\hline $\begin{array}{l}\text { ciplinary } \\
\text { ional Ethics }\end{array}$ & $\begin{array}{l}\text { The foundations of moral philosophy and ethical theory as they apply to } \\
\text { professional practice in the human services context. Content includes } \\
\text { standards of practice, ethical codes and ethical decision making in an } \\
\text { interdisciplinary context. }\end{array}$ \\
\hline $\begin{array}{l}\text { Contemporary Mental } \\
\text { Health Practice }\end{array}$ & $\begin{array}{l}\text { Provides students with information about mental health systems, legal } \\
\text { frameworks and policy initiatives, and explores models of recovery, } \\
\text { rehabilitation, intervention and psychoeducation within different } \\
\text { organisational structures. }\end{array}$ \\
\hline $\begin{array}{l}\text { Foundations of } \\
\text { Research Inquiry in } \\
\text { Health }\end{array}$ & $\begin{array}{l}\text { Introduces students to the application of research approaches in health, } \\
\text { social work, human and community services. It aims to provide students } \\
\text { with knowledge, skills and techniques necessary for them to conduct } \\
\text { their own research project. It will also encourage students to critically } \\
\text { examine research methods in terms of their inclusiveness, ethics, validity } \\
\text { and reliability when applied to research in health and human services. }\end{array}$ \\
\hline Mental Health Praxis & Designed to support student learning, personal development and \\
\hline
\end{tabular}




\begin{tabular}{|l|l|}
\hline & $\begin{array}{l}\text { professional practice within a mental health work setting, linked to a 200- } \\
\text { hour professional practice praxis experience to facilitate the } \\
\text { development of mental health practitioner skills. }\end{array}$ \\
\hline Electives (two selected) & $\begin{array}{l}\text { Advances in Suicide Research 1; Applied Counselling; Suicide } \\
\text { Assessment; Comparative Analysis of Different Approaches to Suicidal } \\
\text { Persons; Human Services: Law and Social Policy; Mental Disorder and } \\
\text { Crime; Risk Assessment and Management in Forensic Mental Health; } \\
\text { Healthcare Systems; Health Economics; Health Informatics; Change } \\
\text { Management in Dynamic Healthcare Systems; Health Finance and } \\
\text { Project Management; Directions in Mental Health; Quantitative } \\
\text { Research; Qualitative Research; Health Leadership and Management; } \\
\text { Contemporary Suicide Prevention Practice II; Advances in Suicide } \\
\text { Research 2; Perspectives on Disability; Working in Organisations; Co } \\
\text { morbidity in Mental Health; Forensic Mental Health Legislation and } \\
\text { Policies; Health Promotion Community Engagement; Working with } \\
\text { Families in Illness and Health; Interventions and Recovery in Forensic } \\
\text { Mental Health }\end{array}$ \\
* Graduate Certificate qualification consists of the first four core courses, Master qualification consists \\
of all courses and two electives.
\end{tabular}

In this paper we report specific findings that explore the perspectives of different external stakeholders on the issues associated with interprofessional mental health workforce practice. These identified issues may warrant consideration by education providers when developing interprofessional curriculum to meet learning needs of mental health practitioners from different discipline backgrounds. It is hoped that by preparing to work collaboratively, mental health workers will be able to recognise, respect and value the role and expertise of consumers, family members and other mental health professionals involved in the provision of care. Effective and respectful collaboration is an important element in the promotion of choice and control for consumers, assisting recovery and citizenship (Le Boutillier \& Croucher, 2010).

\section{Method}

Eight external stakeholders were interviewed to provide perspectives on workforce needs, the postgraduate program and issues associated with mental health professional education. Stakeholders participated in 50-70 minute in-depth semi-structured interviews (face-to-face $\mathrm{n}=4$; telephone $\mathrm{n}=4$ ). Stakeholders included three nursing representatives (senior practitioners and members of the credentialing board), two social work senior practitioners, two representatives from the community mental health workforce and a mental health service-user. Stakeholders were selected via a purposive sampling method allowing researchers to recruit individuals who would be relevant to this study and be the most informative in answering the proposed questions. Participants were asked to reflect on a range of perspectives, professions and settings with regards to mental health practice. Interviews focused on interprofessional and discipline/context workforce learning and development issues and program content requirements.

Interviews were audio-recorded and transcribed verbatim. Ethics approval was obtained from the university Human Research Ethics Committee. Thematic analysis was used to analyse the data. Initially, extracts of the text from each interview were analysed and condensed into units of meaning (Graneheim \& Lundman, 2004). The condensed meaning units were then clustered according to commonalities of meaning (Graneheim \& Lundman, 2004) and classified into descriptive categories with supporting examples (Polit \& Beck, 2006). A second researcher completed independent data checks, to confirm consistency between transcripts, units of meaning and the final summary. 


\section{Results}

Practice frameworks, workforce and training issues were interpreted and applied differently by stakeholders from different settings (Table 2). Different discipline contexts (e.g. social work, nursing, support worker) and practice settings (clinical, e.g. public health sector; and community, e.g. non-government organisations) influenced how these concepts were emphasised and integrated into practice. For the purpose of this paper, the authors will refer to clinical settings as the public mental health sector (hospital and community services funded by the Government with a focus on clinical management of illness), and community settings as the non-government services that provide support services (accommodation, employment, social, recreational support and advocacy). The following results are explained according to context and the three emerging subthemes: a) practice frameworks; b) workforce issues; and c) postgraduate mental health practice program with example quotes (Table 2).

Table 2. Key themes emerging

\begin{tabular}{|c|c|c|}
\hline Theme & Sub-Themes & Issues \\
\hline \multirow[t]{3}{*}{$\begin{array}{l}\text { Tension between } \\
\text { different service } \\
\text { contexts: clinical } \\
\text { versus } \\
\text { community }\end{array}$} & $\begin{array}{l}\text { Practice } \\
\text { frameworks }\end{array}$ & $\begin{array}{l}\text { Therapeutic relationship } \\
\text { "We are [the] intervention. I guess really understanding the } \\
\text { therapeutic relationship. But at the same time it has to be } \\
\text { balanced with a really sound understanding of boundaries } \\
\text { and professionalism" (clinical) } \\
\text { Recovery } \\
\text { "She gave me the tools to then help myself again, in which } \\
\text { case I contacted my doctor and subsequently a psychologist" } \\
\text { (consumer) } \\
\text { "...it seems that they just put a virtual plaster on people, from } \\
\text { what I've seen, and send them back out" (consumer) } \\
\text { Professional identities } \\
\text { "they don't know what they are bringing that is uniquely } \\
\text { mental health" (clinical) }\end{array}$ \\
\hline & Workforce & $\begin{array}{l}\text { Qualifications } \\
\text { "I'll interview people with doctorates but I wouldn't employ } \\
\text { them here, just simply because of attitude" (community) } \\
\text { "Qualifications are very useful in terms of informing the } \\
\text { person, but if they don't have the personality to fit with the } \\
\text {...model, then it's just not going to happen" (community) } \\
\text { New graduates \& entry transition programs } \\
\text { "We get new grads who are unable to do basic mental health, } \\
\text { like proper mental states, examinations.... they can't do any } \\
\text { of that. So we're actually re-training people and } \\
\text { [organisation] have an entire section where they are now re- } \\
\text { training people within the first two years because they didn't } \\
\text { get it in their undergraduate training" (clinical) } \\
\text { Placement } \\
\text { "a chance for people to just sit with people and learn that well } \\
\text { there's nothing to be scared of (community) } \\
\text { You may have the knowledge but you won't have the skill } \\
\text { unless you have placements in your training" (clinical) }\end{array}$ \\
\hline & $\begin{array}{l}\text { Postgraduate } \\
\text { mental health } \\
\text { practice } \\
\text { program }\end{array}$ & $\begin{array}{l}\text { Content } \\
\text { "I would have difficulty recommending this course because } \\
\text { it's multidisciplinary so that would not fit within our } \\
\text { credentialing for their career path" (clinical) } \\
\text { "It's covering off a range of people and a range of needs. In } \\
\text { fact, it's a really good selection. So it doesn't force anybody } \\
\text { down a particular pathway just because that is all that's }\end{array}$ \\
\hline
\end{tabular}


offered" (clinical)

Interprofessionalism

"Look[ing] at another discipline like say OT [Occupational

Therapy] or social work... I think that would be beneficial

because then it opens up that perspective as well...that's a

multidisciplinary approach..."(clinical)

\section{Practice frameworks}

Practice frameworks related to the key principles and professional approaches that practitioners were guided by when working with people with mental illness. Within the clinical/health context, regardless of discipline, understanding the therapeutic relationship was seen as an essential requirement acknowledging the worker as the therapeutic tool in any intervention. Recovery and respect of the individual consumer experience were seen as important elements of this relationship, however the community/non-government context emphasised assisting people to explore their strengths and reconnect as citizens rather than focussing on illness. These aspects promote the development of new personal meanings that go beyond the illness experience, valuing social empowerment and participation (Cobigo \& Stuart, 2010). A focus on relationship is consistent with the service-user perspective, where the human face of healthcare was highly valued and highlighted the importance of consumer-practitioner relationships irrespective of disciplines, roles (including non-professionals) and settings. This has important implications for IPE, indicating that a common point of learning for all mental health education requires an emphasis on building positive relationships regardless of the professional approach taken to achieve this. The current program utilises lived experience narratives as a central theme in all courses to highlight the importance of relationship building and supporting recovery through connectedness (Petros, Solomon, Linz, DeCesaris, \& Hanrahan, 2015).

Understanding recovery frameworks was identified by stakeholders as a key requirement of postgraduate education. This was seen as particularly crucial within the community context, as understanding the lived experiences of people and the role that systems/services play in keeping or making people unwell, or enabling or constraining social participation, is seen as an underpinning principle of practice. Exploring how different professions describe and integrate recovery frameworks in their practice was seen as an important component in a tertiary level IPE program and as a result recovery-oriented content and assessment items were strengthened in a number of courses within the program.

Practitioners' professional and role identity issues within the current mental health system were discussed. For example, within clinical settings, social workers found it difficult to identify discipline specific skills they contributed to multidisciplinary mental health teams while nurses viewed social workers as 'good value' generic case managers. In the community context however, social workers were able to more clearly define their practice as consistent with working within a recovery framework, identifying congruence in values and approaches. This variation between contexts and disciplines highlights the need for openly exploring and clarifying professional identities as well as collaborative practice in postgraduate IPE programs with the aim of reducing barriers to interprofessional mental health practice.

\section{Workforce issues}

The minimum qualification or skills desired for entry into mental health work varied according to professional role and clinical/community context. The community setting typically employed a range of workers including peer support workers (often without tertiary qualifications), and personal attributes, such as empathy and compassion were viewed as more important than qualifications. However, the clinical sector perceived the need for a highly professionalised and qualified workforce. For example, the nursing profession was seen as requiring a highly structured transition program following undergraduate qualification 
attainment to be able to work in mental health. In contrast, the consumer stakeholder identified that the most important workforce requirements were that staff were personcentred in their approach and supported choice, freedom and equality.

Whilst undergraduate education was seen to provide a breadth of knowledge, stakeholders felt that mental health skills were learnt on the job through good supervision. Working in the clinical context was identified as a difficult transition for under-prepared new nursing graduates who often required additional support and re-training due to knowledge and skills deficits. The community sector had similar issues with underprepared new workers however pursuing higher education held little incentive for workers in this sector, as pay levels did not alter after qualification attainment. Additionally clinical employees were reported to start at a much higher base salary making new graduate attraction to the community sector difficult. Therefore, an IPE approach needs to be sensitive to these issues and work-based placements were seen as an opportunity to resolve some of these issues: placements were thought to assist students to overcome their fears, develop confidence working with mental health consumers and carers, as well as attracting students into mental health work.

\section{Postgraduate mental health practice program}

Overall the content of the postgraduate IPE program was viewed as appropriate, with some additions and revisions suggested to make it more relevant to the various professions in both clinical and community settings. The interprofessional approach was appreciated by all stakeholders but was not always seen to meet an individual professional's needs. For example, nursing stakeholders identified the need to have a nursing skills focus within postgraduate education to meet credentialing requirements. The interdisciplinary approach and focus on interdisciplinary ethics and therapeutic approaches was appreciated but was not seen to entirely meet their profession's needs. Providing options for nursing specific electives within the program was perceived as a positive outcome by these stakeholders. In contrast, within the community sector, there was a focus on how education can support practitioners to work more effectively with consumers in their recovery journey. In general on-line education was considered a useful learning delivery mode.

\section{Discussion}

The stakeholders interviewed represented a spread of perspectives on mental health service delivery and perceptions of the postgraduate program. Different workforce settings and disciplines recognised the importance of interprofessional approaches but articulated a need for clear professional identity and discipline specific skills within the mental health workforce, highlighting the need for an adaptive interprofessional program. Although the language used and service models varied between disciplines and settings, there were underlying similarities (e.g. therapeutic relationship, person-centred practice) that can enhance interprofessional approaches to working in the mental health sector. Providers taking an IPE approach need to capture the wide-ranging needs of their audience and deliver programs that assist in building interprofessional understanding to ensure consumer needs are met. Having a broader understanding of practice frameworks used by members of an interprofessional team (differences and similarities) would potentially improve outcomes for consumers through increased collaboration. Through collaboration and recovery, people experiencing a mental illness are assisted to (re)build a sense of wholeness and engaged citizenship, increasing social and economic participation in the community (Petros et al., 2015).

As a result of this evaluation, a number of changes were made to the program to better meet the needs of students and stakeholders. To increase discipline specific content and information, electives were reviewed and students provided with opportunities to enrol in 
relevant courses from within a range of health disciplines including nursing, social work, psychology and public health. Additionally, all assessment items in the core courses were revised to ensure that there were opportunities for students to research and focus on issues relevant to their own discipline, utilising discipline specific literature and frameworks. It was also identified that there were potential advantages to students engaging in work-based learning experiences at an advanced level to assist with the development of new forms and understanding of practice (Fowler \& McGarry, 2011). In response to this, a work-based Mental Health Praxis course has been developed with a focus on professional deliberation (Connor, 2004) to assist in the development of advanced skills (Stewart, Campbell, \& Wheeler, 2016). Praxis activities are to be supervised by staff from relevant disciplines aligned with student learning goals.

The challenge for postgraduate education providers is to meet specific discipline needs, while providing opportunities for students to learn together, understand their own role and those of others, to spend time exploring each other's belief and value systems and to share their expertise and knowledge (Howkins, 2007). The current study is limited by its small sample size and specific evaluation intent, therefore caution in generalising the result is recommended. However, the results provide an insight into the innovative course and program design needed to respond to interprofessional learning in postgraduate mental health and ensure workforce training is aligned with the needs of consumers to ensure they are able to participate effectively in community life. 


\section{References}

Barr, H., Koppel, I., Reeves, S., Hammick, M., \& Freeth, D. (2005). Effective interprofessional education: Argument, assumption and evidence. Oxford: Blackwell

Cobigo, V., \& Stuart, H. (2010). Social inclusion and mental health. Current Opinion in Psychiatry, 23(5), 453-457. doi:10.1097/YCO.0b013e32833bb305

Commonwealth of Australia. (2009). National mental health policy 2008.

Connor, M. J. (2004). The practical discourse in philosophy and nursing: An exploration of linkages and shifts in the evolution of praxis. Nursing Philosophy, 5(1), 54-66. Retrieved from http://libraryproxy.griffith.edu.au/login?url=http://search.ebscohost.com/login.aspx?dir ect=true \&db=rzh\&AN=2004189537\&site=ehost-live\&scope=site

Currie, A. (2011). Recovery, social inclusion and the practice of psychiatrists. Mental Health and Social Inclusion, 15(3), 143-150. doi:10.1108/20428301111165735

Duckett, S. (2005). Interventions to facilitate health workforce restructure. Australia and New Zealand Health Policy, 2(1), 14. doi:10.1186/1743-8462-2-14

Fowler, C., \& McGarry, D. (2011). Praxis: The essential nursing construct. In A. Cashin \& R. Cook (Eds.), Evidence-based practice in nursing informatics: Concepts and applications (pp. 40-50). Hershey, PA, USA: IGI Global.

Graneheim, U. H., \& Lundman, B. (2004). Qualitative content analysis in nursing research: Concepts, procedures and measures to achieve trustworthiness. Nurse Education Today, 24(2), 105-112. doi:10.1016/j.nedt.2003.10.001

Hannigan, B., \& Allen, D. (2011). Giving a fig about roles: Policy, context and work in community mental health care. Journal of Psychiatric and Mental Health Nursing. doi:10.1111/j.1365-2850.2010.01631.x

Henderson, J., Willis, E., Walter, B., \& Toffoli, L. (2008). Community mental health nursing: Keeping pace with care delivery? International Journal of Mental Health Nursing, 17(3), 162-170. doi:10.1111/j.1447-0349.2008.00528.x

Howkins, E. (2007). Perspectives of interprofessional learning and teaching: Theory and practice. In E. a. B. Howkins, J. (Ed.), Preparing for interprofessional teaching: Theory and practice (pp. 1-12). Oxford, U.K: Radcliffe Publishing.

Le Boutillier, C., \& Croucher, A. (2010). Social inclusion and mental health. British Journal of Occupational Therapy, 73, 136-139.

McAllister, M., Statham, D., Oprescu, F., Barr, N., Schmidt, T., Boulter, C., . . . Raith, L. (2014). Mental health interprofessional education for health professions students: Bridging the gaps. Journal of Mental Health Training, Education and Practice, 9(1), 35-45. doi:10.1108/JMHTEP-09-2012-0030

Meadows, G. N., \& Burgess, P. M. (2009). Perceived need for mental health care: Findings from the 2007 australian survey of mental health and wellbeing. Australian and New Zealand Journal of Psychiatry, 43(7), 624-634. doi:10.1080/00048670902970866

Petros, R., Solomon, P., Linz, S., DeCesaris, M., \& Hanrahan, N. P. (2015). Autovideography: The lived experience of recovery for adults with serious mental illness. Psychiatric Quarterly, 1-10. doi:10.1007/s11126-015-9397-8

Polit, D. F., \& Beck, S. T. (2006). Essentials of nursing research: Methods, appraisal, and utilization (6th ed.). Sydney: Lippincott, Williams and Wilkins.

Productivity Commission. (2005). Australia's health workforce. Canberra: Productivity Commission Retrieved from http://www.pc.gov.au/projects/study/health-workforce.

Stewart, V., Campbell, M., \& Wheeler, A. J. (2016). Developing a postgraduate work-based curriculum using an intervention mapping approach. Studies in Continuing Education, 1-16. doi:10.1080/0158037X.2015.1120192

Stewart, V., Fielden, J., Harris, M., \& Wheeler, A. J. (2012). Making mental health practitioners workforce ready. Journal of Mental Health Training, Education and Practice, 7(3), 124-132. doi:10.1108/17556221211269938 
The Interprofessional Curriculum Renewal Consortium Australia. (2013). Interprofessional education: A national audit. Report to health workforce australia. Retrieved from http://umanitoba.ca/programs/interprofessional/media/IPE_National_Audit_Report_A ustralia_2013(1).pdf

Vize, C. (2009). New ways of working and the issue of responsibility and accountability. Journal of Mental Health Training, Education and Practice, 4(2), 8-12.

\section{Biographical notes}

Victoria Stewart is a Lecturer in the postgraduate mental health practice programs at Griffith University. She has over 23 years' experience in mental health as a practitioner, educator and researcher. She has practiced in Australia, U.K. and U.S.A, in a variety of roles and services, working within a number of models of care. Her research and education role is focused on recovery-oriented practice and improving service experiences for consumers and carers.

Michelle Crozier has worked and played in the human service sector supporting people who may experience vulnerability for over 20 years. She has experience in service management, academic research, project management and consultancy, as well as lived experience at the hands of different service systems (e.g. health and education). At the heart of who she is an ongoing commitment to see inclusive and welcoming communities that reduce the vulnerability of people who can be dependent on systems.

Professor of Mental Health at Griffith University. She has worked as a health practitioner, educator and researcher in mental health and pharmacy practice for almost 20 years. She is nationally and internationally recognised for her expertise in these areas. Her research focuses on quality improvement, professional practice, workforce development and capacity building. These themes come together with the common goal of improving outcomes for consumers and carers and are integrated across the full scope of her work. 